\title{
ANALISIS KELAYAKAN DAN SENSITIVITAS: STUDI KASUS INDUSTRI KECIL TEMPE KOPTI SEMANAN, KECAMATAN KALIDERES, JAKARTA BARAT
}

\author{
Etty Susilowati $^{1}$, Haruni Kurniati ${ }^{2}$ \\ Universitas Budi Luhur ${ }^{1,2}$ \\ Email korespondensi: ettysslwt@gmail.com
}

\begin{abstract}
The small manufacturing sector has a large role in the processing of agricultural products and helps provide employment and business opportunities in an effort to encourage regional and rural development. The small industrial estate (PIK) of KOPTI Semanan in Kalideres Subdistrict, West Jakarta is one of the fermented soybean processing centers in Jakarta. In running its business, PIK KOPTI Semanan faces internal and external constraints so it has not been able to achieve business development as expected. The purpose of this research was to analyze the feasibility and sensitivity of small industry enterprises in Kalideres Subdistrict, West Jakarta. Net Present Value (NPV), Internal Rate of Return (IRR), Payback Period (PP), and Net Benefit Cost Ratio (Net B/C) methods were employed to calculate the financial feasibility of small fermented soybean industry enterprises. While the sensitivity analysis is done by doing the scenario of decreasing and increasing cost and price. The results of the analysis indicated that the small fermented soybean industry in Kalideres District is feasible to be implemented. However, the sensitivity analysis results indicated 3 out of 5 enterprises were sensitive to decreased revenue and increased costs.
\end{abstract}

Keywords: small industry enterprises; fermented soybean; feasibility study; sensitivity analysis

Received: 15 Pebruari 2018 Reviewed: 21 Pebruari 2018

Accepted: 7 April 2018

Published: 19 April 2018

\section{PENDAHULUAN}

Sektor industri pengolahan merupakan salah satu penyumbang dalam meningkatkan perekonomian di Indonesia. Keberadaan sektor industri pengolahan merupakan salah satu motor penggerak yang penting bagi pertumbuhan ekonomi Indonesia. Industri pengolahan pangan merupakan industri yang bergerak dalam pengolahan hasil pertanian, baik nabati maupun hewani menjadi produk pangan olahan, yang dapat dibuat dan dikembangkan dari sumber daya alam lokal. Saat ini Indonesia memiliki banyak produk pangan yang diangkat dari jenis pangan lokal dan diolah secara tradisional. Perkembangan produk lokal akan menambah jumlah dan jenis produk pangan (Soleh, 2003). 
Pengembangan industri kecil adalah cara yang dinilai besar peranannya dalam pengembangan industri manufaktur. Pengembangan industri kecil akan membantu mengatasi masalah pengangguran mengingat teknologi yang digunakan adalah teknologi padat karya sehingga bisa memperbesar lapangan kerja dan kesempatan usaha, yang pada gilirannya mendorong pembangunan daerah dan kawasan pedesaan (Kuncoro, 2007). Industri kecil yang mengolah hasil-hasil pertanian dan mampu bertahan terhadap dampak krisis ekonomi merupakan salah satu alternatif dalam membangun kembali perkonomian Indonesia saat ini (Anoraga dan Sudantoko, 2002). Selain dapat menciptakan lapangan pekerjaan bagi masyarakat sekitar perusahaan, industri kecil juga dapat menciptakan nilai tambah bagi produk pertanian. Salah satu industri kecil yang potensial untuk dikembangkan adalah pabrik pembuatan tempe. Konsumen tempe sangat luas dan mencakup semua strata sosial. Tempe tidak hanya di konsumsi oleh masyarakat kelas bawah, dan menengah saja, akan tetapi juga kelas atas. Hal ini dapat dilihat telah masuknya banyak produk tempe di pasar tradisional sampai retail modern.

Beberapa penelitian sebelumnya telah banyak yang membahas analisis kelayakan dan sensitivitas usaha produk pangan (Maulidah et al., 2010; Indradi et al., 2013; Nurainy et al., Yuwani et al., 2014; 2015), kelayakan usaha kecil (Abou-Moghli \& Al-Abdallah, 2012; Afiyah et al., 2015; Oke et al., 2015) dan kelayakan usaha non pangan (Adriano \& Anggono, 2013). Meski demikian analisis kelayakan usaha menjadi topik yang tetap menjadi menarik untuk dianalisis karena setiap usaha memiliki kekuatan, kelemahan, peluang dan ancaman masing-masing yang berbeda dengan usaha lainnya.

Primer Koperasi Produksi Tahu Tempe Indonesia (PRIM KOPTI) merupakan salah satu koperasi yang melakukan pengolahan tempe di Jakarta. Koperasi ini tersebar dan bercampur dengan kawasan pemukiman penduduk di wilayah Tambora I, Tambora II-Grogol, Kebon Jeruk dan Cengkareng. Pada tahun 1990, Koperasi ini berhasil membeli tanah milik Puskoptinas seluas 12 ha di Kelurahan Semanan, Kecamatan Kalideres Jakarta Barat, yang digunakan sebagai lahan untuk pembangunan rumah tinggal sekaligus tempat produksi bagi anggota koperasi dan mengubah nama koperasi menjadi Perkampungan Industri Kecil (PIK) KOPTI Semanan. PIK KOPTI Semanan memiliki jumlah anggota 735 orang dan calon anggota 682 orang. Sedangkan jumlah pengrajin mencapai 1.173 pengrajin, dengan total 2.315 pekerja. Total keseluruhan kedelai yang dibutuhkan per harinya mencapai $61.910 \mathrm{~kg}$. Sebagian pengrajin tempe dan tahu juga memproduksi produk turunan tempe, seperti oncom, tempe gembus, tempe keripik, dan produk lainnya, seperti lontong, kerupuk kulit dan kerupuk rambak.

Dalam menjalankan kegiatan usahanya, PIK KOPTI Semanan masih terkendala sarana produksi yang masih mengandalkan alat-alat dan metode tradisional. Akibatnya kapasitas serta kualitas produksi yang dihasilkan masih jauh dari yang diharapkan. Padahal kegiatan usaha ini sudah mulai dirintis sejak 
tahun 1972 oleh para pengrajin tahu tempe yang mayoritas berasal dari Pekalongan Jawa Tengah. Namun ternyata pengalaman menjalankan usaha selama hampir 45 tahun belum mampu membawa usaha sebagaimana yang diharapkan para pengrajin tahu tempe. Berdasarkan latar belakang tersebut, maka tujuan penelitian ini adalah untuk: 1) menganalisis kelayakan usaha industri kecil tempe di Kecamatan Kalideres, Jakarta Barat, dan 2) menganalisis tingkat sensitivitas industri kecil tempe di Kecamatan Kalideres terhadap perubahanperubahan pada manfaat dan biaya.

\section{Analisis Kelayakan Usaha}

Analisis kelayakan usaha adalah suatu kegiatan untuk menilai sejauh mana manfaat yang dapat diperoleh dalam melaksanakan suatu kegiatan usaha agar dapat mengurangi risiko yang dihadapi di masa depan. Studi ini dilakukan sebagai bahan pertimbangan dalam mengambil suatu keputusan, apakah meneriman atau menolak dari suatu gagasan usaha yang direncanakan (Kasmir \& Jakfar, 2003). Pengertian layak dalam penilaian ini adalah kemungkinan dari gagasan usaha yang akan dilaksanakan memberikan manfaat, baik manfaat ekonomi maupun sosial. Kegiatan usaha yang memberikan manfaat ekonomi pada umumnya adalah kegiatan yang manfaatnya dihitung dari segi manfaat yang diberikan usaha terhadap perkembangan perekonomian masyarakat secara keseluruhan. Sedangkan kegiatan usaha dinilai memberikan manfaat ekonomi dinilai dari segi penanaman investasi/modal yang diberikan untuk pelaksanaan usaha/proyek tersebut (Sulastri, 2016). Penelitian-penelitian sebelumnya telah menganalisis mengenai kelayakan usaha tahu dan tempe Nurhayati, Hubeis, \& Raharja (2012), Mujiningsih (2013), Mar'atissholikhah, Darsono, \& Nurjayanti (2013), Rahmawati (2014), Pratiwi, Hartono, \& Suryantini (2016). Secara umum, berdasarkan penelitian terdahulu, usaha pengrajin tahu dan tempe layak untuk diusahakan. Namun fluktuasi dan gejolak pada laju inflasi dan nilai tukar rupiah terhadap dollar per tahun mengakibatkan analisis kelayakan usaha tempe masih akurat untuk dilakukan untuk menganalisis bagaimana respon perubahan harga bahan bakar, bahan baku serta biaya-biaya lainnya terhadap keberlangsungan usaha ini.

\section{Kriteria Kelayakan Investasi}

Kriteria kelayakan investasi yang digunakan pada penelitian ini meliputi Net Present Value (NPV), Internal Rate of Return (IRR), Payback Period (PP), dan Rasio Benefit/Cost (B/C).

\section{Net Present Value (NPV)}

Net Present Value (NPV) atau nilai bersih sekarang yaitu selisih antara Present Value dari investasi dengan nilai sekarang dari penerimaan penerimaan 
kas bersih di masa yang akan datang. Sebuah usaha dinilai layak apabila nilai NPV > 0 (Husein, 2003). Rumus yang digunakan untuk menghitung NPV adalah sebagai berikut (Husein, 2003).

$$
\mathrm{NPV}=\sum_{t=1}^{n} \frac{C F t}{(1+K)^{t}}-I_{0}
$$

Keterangan:

$\mathrm{CFt}=$ aliran kas pada tahun ke-t

$\mathrm{I}_{0} \quad$ = investasi pada $\mathrm{t}=0$

$\mathrm{K}=$ discount rate

\section{Internal Rate of Return (IRR)}

Internal rate of return (IRR) adalah merupakan metode yang digunakan untuk mencari tingkat bunga yang menyamakan nilai sekarang dari arus kas yang diharapkan di masa datang atau penerimaan kas, dengan mengeluarkan investasi awal. Sebuah usaha dinilai layak apabila nilai IRR > tingkat pengembalian yang ditentukan (Husein, 2003). Rumus yang digunakan untuk menghitung IRR adalah sebagai berikut (Husein, 2003):

$$
\operatorname{IRR}=P_{1}-C_{1} x \frac{P_{2}-P_{1}}{C_{2}-C_{1}}
$$

Keterangan:

$\mathrm{P}_{1} \quad=$ suku bunga pertama

$\mathrm{P}_{2} \quad=$ suku bunga kedua

$\mathrm{C}_{1} \quad=$ NPV pertama

$\mathrm{C}_{2} \quad=$ NPV kedua

\section{Payback Period (PP)}

Payback period (PP) adalah suatu periode yang menunjukkan berapa lama modal yang ditanamkan dalam usaha dapat kembali. Sebuah usaha dinilai layak apabila nilai PP lebih kecil dari nilai PP maksimum (Husein, 2003). Rumus yang digunakan untuk menghitung PP adalah sebagai berikut (Husein, 2003).

$$
\mathrm{PP}=\frac{\text { Nilai investasi }}{\text { Kas masuk bersih }} \times 1 \text { tahun }
$$

\section{Rasio Benefit/Cost (B/C)}

Rasio B/C merupakan metode yang dilakukan untuk melihat berapa manfaat yang diterima oleh usaha untuk satu rupiah pengeluaran. Menurut Sofyan (2004), rasio $\mathrm{B} / \mathrm{C}$ adalah suatu rasio yang membandingkan antara benefit atau penerimaan dari suatu usaha dengan biaya yang dikeluarkan untuk merealisasikan rencana pendirian dan pengoperasian usaha tersebut. Sebuah usaha dinilai layak apabila nilai Net B/C > 1 (Husein, 2003). Rumus yang digunakan untuk menghitung rasio B/C adalah sebagai berikut (Husein, 2003).

$$
\text { Net } B / C \text { ratio }=\frac{\sum_{t=0}^{t=n}(N P V)(+)}{\sum_{t=0}^{t=n}(N P V)(-)}
$$


Keterangan: NPV $=$ Net Present Value

\section{Tingkat Pengembalian yang Diharapkan (Expected Return)}

Tingkat pengembalian yang diharapkan $\left(E\left(R_{i}\right)\right)$ pada usaha merupakan keuntungan riil yang diestimasi oleh investor. Rumus yang digunakan untuk menghitung $E\left(R_{i}\right)$ adalah (Hartono, 2014):

$$
E\left(R_{i}\right)=R_{f}+\beta i\left[E\left(R_{m}\right)-R_{f}\right]
$$

Keterangan:

$\mathrm{E}\left(\mathrm{R}_{\mathrm{i}}\right)$ = tingkat pengembalian yang diharapkan

$\mathrm{R}_{\mathrm{f}} \quad=$ tingkat keuntungan bebas risiko

$\beta \mathrm{i} \quad=$ alpha portofolio

$\mathrm{R}_{\mathrm{m}} \quad=$ tingkat pengembalian pasar

\section{Analisis Sensitivitas Usaha}

Analisis sensitivitas adalah suatu analisa untuk dapat melihat pengaruhpengaruh yang akan terjadi akibat keadaan yang berubah-ubah (Gittinger 1986). Pada bidang pertanian, perubahan yang terjadi pada kegiatan usaha dapat diakibatkan oleh empat faktor utama yaitu perubahan harga jual produk, keterlambatan pelaksanaan usaha, kenaikan biaya dan perubahan volume produksi. Analisis sensitivitas dilakukan dengan mencari beberapa nilai pengganti pada komponen biaya dan manfaat yang masih memenuhi kriteria minimum kelayakan investasi atau maksimum nilai NPV sama dengan nol, nilai IRR sama dengan tingkat suku bunga dan $\mathrm{Net}$ B/C ratio sama dengan 1 (cateris paribus) (Gittinger, 1986).

Parameter harga jual produk, jumlah penjualan dan biaya dalam analisis finansial diasumsikan tetap setiap tahunnya (cateris paribus). Namun, dalam keadaan nyata ketiga parameter dapat berubah-ubah sejalan dengan pertambahan waktu. Untuk itu, analisis sensitivitas perlu dilakukan untuk melihat sampai berapa persen penuruan harga atau kenaikan biaya yang terjadi dapat mengakibatkan perubahan dalam kriteria kelayakan investasi dari layak menjadi tidak layak (Gittinger, 1986).

\section{METODE PENELITIAN}

Penelitian ini bersifat deskriptif kuantitatif dengan menggunakan data primer dan data sekunder. Data primer diperoleh dengan cara observasi dan kuesioner. Sedangkan data sekunder diperoleh dari berbagai literatur. Teknik pengambilan sampel menggunakan Purposive Sampling, dengan sampel pengrajin tempe sejumlah lima pengrajin tempe di Kecamatan Kalideres, Jakarta Barat. Pengumpulan data dilakukan pada bulan Pebruari 2017. 
Tabel 1. Definisi Operasional Variabel Penelitian

\begin{tabular}{|c|c|c|c|c|}
\hline No. & Variabel & Konsep Teoritis & Indikator & Skala \\
\hline 1 & Modal & \begin{tabular}{lcr} 
Dana yang & digunakan & untuk \\
membiayai & \multicolumn{2}{c}{ operasional } \\
perusahaan & dalam & proses \\
produksi (Munawir, 2010).
\end{tabular} & $\begin{array}{l}\text { Sumber modal, biaya } \\
\text { pengadaan peralatan } \\
\text { produksi, dan biaya } \\
\text { operasional produksi }\end{array}$ & Rasio \\
\hline 2 & $\begin{array}{l}\text { Tenaga } \\
\text { kerja }\end{array}$ & $\begin{array}{l}\text { Para pekerja yang dipekerjakan } \\
\text { untuk melakukan aktivitas- } \\
\text { aktivitas dalam proses produksi } \\
\text { (UU No. } 13 \text { Tahun 2003) }\end{array}$ & $\begin{array}{l}\text { Jumlah tenaga kerja } \\
\text { industri kecil tempe di } \\
\text { Kecamatan Kalideres, } \\
\text { Jakarta Barat }\end{array}$ & Rasio \\
\hline 3 & Bahan baku & $\begin{array}{l}\text { Bahan mentah yang menjadi } \\
\text { dasar pembuatan suatu produk } \\
\text { yang mana bahan tersebut dapat } \\
\text { diolah melalui proses tertentu } \\
\text { untuk dijadikan wujud lain } \\
\text { (Skousen, 2001). }\end{array}$ & $\begin{array}{l}\text { Asal bahan baku dan } \\
\text { jenis bahan baku }\end{array}$ & Nominal \\
\hline 4 & Teknologi & $\begin{array}{l}\text { Pengembangan dan aplikasi dari } \\
\text { alat, mesin, material dan proses } \\
\text { yang menolong } \\
\text { menyelesaikan mansia } \\
\text { (Husein, 2003) }\end{array}$ & $\begin{array}{l}\text { Peralatan yang } \\
\text { digunakan dalam proses } \\
\text { produksi tempe }\end{array}$ & Nominal \\
\hline 5 & Produksi & $\begin{array}{l}\text { Kegiatan yang menciptakan, } \\
\text { mengolah, mengupayakan } \\
\text { pelayanan, menghasilkan barang } \\
\text { dan jasa atau usaha untuk } \\
\text { meningkatkan suatu benda agar } \\
\text { menjadi lebih berguna bagi } \\
\text { kebutuhan manusia (Assauri, } \\
\text { 1995) }\end{array}$ & $\begin{array}{l}\text { Jenis produksi, } \text { jumlah } \\
\text { produksi dan lama } \\
\text { proses produksi. }\end{array}$ & $\begin{array}{l}\text { Nominal, } \\
\text { interval } \\
\text { dan rasio }\end{array}$ \\
\hline 6 & Pemasaran & $\begin{array}{l}\text { Proses menghasilkan produk } \\
\text { untuk menciptakan kepuasan bagi } \\
\text { konsumen (Kotler \& Amstrong, } \\
\text { 2008) }\end{array}$ & $\begin{array}{l}\text { Unit yang terjual dan } \\
\text { daerah sasaran }\end{array}$ & $\begin{array}{l}\text { Rasio dan } \\
\text { nominal }\end{array}$ \\
\hline 7 & $\begin{array}{l}\text { Kelayakan } \\
\text { finansial }\end{array}$ & $\begin{array}{l}\text { Indikator yang digunakan yang } \\
\text { menunjukkan bahwa industri } \\
\text { kecil tempe di Kecamatan } \\
\text { Kalideres, Jakarta Barat, } \\
\text { pelaksanaan sudah layak atau } \\
\text { belum (Husein, 2003) }\end{array}$ & $\begin{array}{l}\text { Net Present Value } \\
(\mathrm{NPV}), \text { Internal Rate of } \\
\text { Return (IRR), Payback } \\
\text { Period (PP), Net Benefit } \\
\text { Cost Ratio }(\text { Net B/C). }\end{array}$ & Rasio \\
\hline
\end{tabular}

Sumber: Data diolah penulis.

Analisis data dilakukan dengan analisis kelayakan finansial, dan analisis sensitivitas. Analisis kelayakan finansial dilakukan untuk mengukur apakah industri kecil tempe yang saat ini dijalankan layak untuk diusahakan di Kecamatan Kalideres Jakarta Barat. Alat analisis yang digunalan adalah Net Present Value (NPV), Internal Rate of Return (IRR), Payback Period (PP), dan Net Benefit Cost Ratio (Net B/C). Net Present Value (NPV) adalah kriteria investasi yang banyak digunakan dalam mengukur apakah suatu proyek feasible atau tidak. Internal Rate of Return (IRR) adalah tingkat diskonto (discount rate) 
yang menjadikan sama antara present value dari penerimaan cash dan present value dari nilai atau investasi discount rate/tingkat diskon yang menunjukan net present value atau sama besarnya dengan nol. Payback period adalah teknik penilaian terhadap jangka waktu (periode) pengembalian investasi suatu proyek atau usaha (Kasmir dan Jakfar, 2004). Net Benefit Cost Ratio (Net B/C) adalah perbandingan antara net benefit yang telah di diskon positif (+) dengan net benefit yang telah di diskon negatif (-). Nilai Net B/C yang lebih besar dari 1 menunjukkan bahwa industri kecil tempe layak untuk diusahakan. Nilai Net B/C lebih kecil dari 1 menunjukkan industri kecil tempe tidak layak untuk diusahakan. Sedangkan nilai $\mathrm{Net} \mathrm{B} / \mathrm{C}$ sama dengan 1 menunjukkan bahwa industri kecil tempe berada pada kondisi Break Even Point (BEP), yaitu total cost sama dengan total revenue. Terakhir, analisis sensitivitas dilakukan dengan melakukan skenario penurunan dan peningkatan biaya dan harga pada industri kecil tempe.

Variabel operasional penelitian ini adalah modal, tenaga kerja, bahan baku, teknologi, dan produksi. Definisi operasional secara lengkap dijelaskan pada Tabel 1.

\section{HASIL DAN PEMBAHASAN}

\section{Biaya Investasi}

Dari hasil wawancara diperoleh biaya investasi yang dipergunakan untuk menyediakan sarana dan prasarana kegiatan produksi usaha industri kecil tempe. Biaya investasi terendah adalah sebesar Rp180.000.000 dan biaya investasi tertinggi adalah sebesar 408.000.000.

Tabel 1. Biaya Tetap Industri Kecil Tempe di Kecamatan Kalideres, Jakarta Barat

\begin{tabular}{llccrcrrrr}
\hline No & Uraian & Jumlah & Unit & Harga & Unit & $\begin{array}{c}\text { Biaya } \\
\text { Tetap }\end{array}$ & Per Hari & Per Bulan & Per Tahun \\
\hline \hline 1 & Kedelai & 200 & Kg & 7.200 & Per Hari & & 1.440 .000 & 43.200 .000 & 518.400 .000 \\
\hline 2 & Ragi & 10 & Kantong & 15.000 & Per Bulan & & - & 1.500 .000 & 18.000 .000 \\
\hline 3 & Plastik & 1 & Kg & 25.000 & Per Hari & & 25.000 & 750.000 & 9.000 .000 \\
\hline 4 & $\begin{array}{l}\text { Daun } \\
\text { Pisang }\end{array}$ & 1 & Ikat & 7.000 & Per Hari & & 7.000 & 210.000 & 2.520 .000 \\
\hline 5 & $\begin{array}{l}\text { Tenaga } \\
\text { Kerja }\end{array}$ & 3 & Orang & 300.000 & Per Hari & & 300.000 & 9.000 .000 & 108.000 .000 \\
\hline 6 & Tabung Gas & 12 & Tabung & 20.000 & Per Bulan & & - & 240.000 & 2.880 .000 \\
\hline 7 & $\begin{array}{l}\text { Listrik, Air, } \\
\text { Telepon }\end{array}$ & & & 900.000 & Per Bulan & & - & 900.000 & 10.800 .000 \\
\hline 8 & Peralatan & & & 300.000 & Per Bulan & & - & 300.00 & 3.600 .000 \\
\hline 9 & $\begin{array}{l}\text { Biaya } \\
\text { Perbaikan }\end{array}$ & & & 500.000 & Per Bulan & & - & 500.000 & 6.000 .000 \\
\hline & & & & & $\mathbf{4 5 . 7 9 0 . 0 0 0}$ & $\mathbf{1 . 7 7 2 . 0 0 0}$ & $\mathbf{5 6 . 5 0 0 . 0 0 0}$ & $\mathbf{7 2 4 . 9 9 0 . 0 0 0}$ \\
\hline
\end{tabular}

Sumber: Data yang telah diolah 


\section{Biaya Tetap dan Biaya Variabel}

Biaya total merupakan jumlah seluruh biaya tetap dan biaya variabel. Biaya tetap industri kecil tempe di Kecamatan Kalideres terdiri dari biaya tenaga kerja tetap, telepon, bahan bakar, pemeliharaan dan perbaikan, dan lain sebagainya seperti dijelaskan di tabel 1 . Sedangkan biaya variabelnya terdiri dari tagihan listrik, bahan baku produksi tempe, dan lain sebagainya. Biaya tetap dan variabel seluruh responden yang diwawancarai pada penelitian ini ditunjukkan pada tabel 2.

Tabel 2. Biaya Tetap dan Biaya Variabel Keseluruhan Responden Penelitian

\begin{tabular}{cccc}
\hline \multirow{2}{*}{ Responden } & \multicolumn{2}{c}{ Biaya Variabel } & \multirow{2}{*}{ Biaya Tetap } \\
\cline { 2 - 3 } & Per Bulan & Per Tahun & \\
\hline \hline 1 & 56.600 .000 & 724.990 .000 & 45.790 .000 \\
\hline 2 & 24.420 .000 & 315.540 .000 & 22.500 .000 \\
\hline 3 & 33.180 .000 & 435.768 .000 & 37.608 .000 \\
\hline 4 & 28.740 .000 & 435.768 .000 & 30.200 .000 \\
\hline 5 & 42.710 .000 & 548.213 .000 & 35.693 .000 \\
\hline
\end{tabular}

Sumber: Data yang telah diolah

\section{Penerimaan}

Penerimaan Pengrajin Tempe di Kecamatan Kalideres rata-rata berjumlah Rp51.096.000 per bulan. Responden 1 yang memproduksi $200 \mathrm{~kg}$ kedelai per hari, menghasilkan jumlah tempe sebanyak 640 potong, dan dijual dengan harga Rp6.000 per potong, jumlah penerimaan per bulannya adalah Rp. 76.800 .000 dan per tahunnya sejumlah Rp. 921.600.000. Responden 2 memproduksi $80 \mathrm{~kg}$ kedelai per hari, menghasilkan 280 potong tempe dengan penerimaan per bulan sebesar Rp33.600.000 dan per tahun sebesar 403.200.000. Responden 3 memproduksi kedelai sebanyak $120 \mathrm{~kg}$ per hari, menghasilkan 384 potong tempe, dengan penerimaan per bulan sebesar Rp. 46.080.000 dan penerimaan per tahun sebesar Rp552.960.000 dan seterusnya.

\section{Arus Kas}

Hasil perhitungan arus kas masing-masing reponden penelitian ditunjukkan pada tabel 5, tabel 6, tabel 7, tabel 8, tabel 9, dan tabel 10. Nilai Cost of Capital (CoC) sebesar $14 \%$ diperoleh dari perhitungan tingkat pengembalian yang diharapkan (Hartono, 2014) sebesar $14 \%$ pada tahun penelitian. Nilai Rf (tingkat bunga bebas resiko) diambil dari Surat Utang Negara seri FR0059 yang diterbitkan oleh Pemerintah Indonesia yaitu 7,79\% per tahun (Kementerian Keuangan, 2017). Nilai $\beta$ sebesar 0,75 didapatkan dari rata-rata semua $\beta$ dari perusahaan publik dibidang pertanian yang terdaftar di Indonesia. Sedangkan untuk premi resiko pasar ( $\mathrm{Rm}$ - Rf) untuk Indonesia sebesar 8,00\% berdasarkan penelitian dari Fernandez et al. (2016). Sehingga dari nilai-nilai tersebut dapat dihitung tingkat pengembaliannya sebagai berikut.

$$
\begin{aligned}
& E(\mathrm{Ri})=\mathrm{Rf}+\beta \mathrm{i}(\mathrm{Rm}-\mathrm{Rf}) \\
& \mathrm{E}(\mathrm{Ri})=7,79 \%+0,75(8 \%)
\end{aligned}
$$


Dengan demikian dalam penelitian ini digunakan tingkat pengembalian sebesar $14 \%$. Nilai ini diasumsikan sama karena kelima responden berada pada wilayah penelitian dan skala usaha yang sama.

\section{Hasil Analisis Kelayakan Usaha}

Hasil analisis kelayakan usaha industri kecil tempe di Kecamatan Kalideres, Jakarta barat ditunjukkan pada lampiran 1. Perhitungan analisis kelayakan dilakukan terhadap kelima responden penelitian dengan memperhitungkan semua biaya dan asumsi usaha yang terjadi untuk 10 tahun kedepan.

Berdasarkan hasil perhitungan analisis kelayakan usaha diperoleh bahwa kelima responden memiliki nilai Net B/C ratio lebih besar dari 1, NPV positif, IRR lebih besar dari tingkat bunga yang ditentukan, dan payback period lebih kecil dari waktu yang ditentukan. Net B/C Ratio menunjukkan kemampuan usaha menghasilkan laba per satuan nilai investasi. Berdasarkan hasil perhitungan menunjukkan nilai net $B / C$ ratio pada usaha responden 1 sebesar 1,2712, nilai net $B / C$ ratio pada usaha responden 2 sebesar 1,2778, nilai net $B / C$ ratio pada usaha responden 3 sebesar 1,2689 , nilai net $B / C$ ratio pada usaha responden 4 sebesar 1,2689 , dan nilai net $B / C$ ratio pada usaha responden 5 sebesar 1,3002 . Nilai tersebut memiliki arti bahwa perbandingan penerimaan dari usaha Industri Kecil Tempe di Kecamatan Kalideres lebih besar daripada jumlah biaya yang dikeluarkan. Dengan kata lain, dari usaha Industri Kecil Tempe akan diperoleh tambahan penerimaan sebesar nilai net $B / C$ dari setiap pengeluaran Rp 1,00. Nilai net $B / C$ ratio tersebut lebih besar dari 1 maka usaha Industri Kecil Tempe di Kecamatan Kalideres layak untuk dilaksanakan.

Selanjutnya, NPV dari kelima pengrajin tempe menunjukkan hasil yang positif, yang artinya memberikan keuntungan karena pada discount factor $14 \%$ per tahun, NPV lebih besar dari nol. NPV pada usaha responden 1 sebesar Rp. 350.912.241, NPV pada usaha responden 2 sebesar Rp. 249.816.966, NPV pada usaha responden 3 sebesar Rp. 273.489.405, NPV pada usaha responden 4 sebesar Rp. 258.686.593, dan NPV pada usaha responden 5 sebesar Rp. 397.155.716. Nilai NPV tersebut menunjukkan bahwa usaha Industri Kecil Tempe di Kecamatan Kalideres layak untuk dilaksanakan.

Hal yang serupa juga berlaku pada nilai IRR usaha para responden penelitian di mana nilai IRR responden 1 sebesar $23,990 \%$, nilai IRR responden 2 sebesar 31,997\%, nilai IRR responden 3 sebesar 26,998\%, nilai IRR responden 4 sebesar 31,990\%, dan nilai IRR responden 5 sebesar 28,990\%. Artinya, tingkat pengembalian internal yang dihasilkan lebih besar nilainya dibandingkan dengan bunga pinjaman bank sebesar 14\% sehingga industri kecil tempe di Kecamatan Kalideres dinilai layak dan menguntungkan untuk dilaksanakan. Terakhir, nilai payback period para responden industri kecil tempe berkisar antara 2,1 tahun, 2,3 
tahun, 2,4 dan 2,8 tahun. Berdasarkan kriteria penilaian mengenai payback period, usaha kelima pengrajin tempe di Kecamatan Kalideres dapat diterima karena jumlah biaya investasi dapat dikembalikan dengan jangka waktu pengembalian investasi kurang dari 10 tahun, yaitu dari waktu yang ditentukan.

\section{Analisis Sensitivitas}

Hasil analisis sensitivitas menunjukkan empat skenario dilakukan pada perhitungan analisis kelayakan usaha kelima responden. Keempat skenario tersebut adalah: 1) penurunan penerimaan sebesar $6 \%$,2) peningkatan harga kedelai sebesar $17 \%, 3$ ) peningkatan harga bahan bakar sebesar $6 \%$, dan 4) peningkatan biaya operasional sebesar $6 \%$. Penentuan nilai persentase kenaikan harga bahan bakar, biaya operasional dan penurunan penerimaan sebesar $6 \%$ didasarkan pada rata-rata laju inflasi Indonesia tahun 2012 sampai 2016 (Bank Indonesia, 2017) sedangkan penentuan nilai persentase kenaikan harga bahan bakar sebesar $6 \%$ didasarkan pada pendekatan presentase nilai tertinggi dan terendah yang dicapai oleh Rupiah terhadap Dollar periode 2012-2016 (Bank Indonesia, 2017). Hasil perhitungan sensitivitas ditunjukkan pada lampiran 2.

Berdasarkan hasil perhitungan analisis sensitivitas yang terdapat pada tabel di atas hanya usaha milik responden 3 dan responden 5 yang dapat dikatakan masih layak untuk dilaksanakan. Ketika penerimaan mengalami penurunan sebesar 6\%, peningkatan harga kedelai sebesar 17\%, peningkatan harga bahan bakar sebesar $6 \%$, dan peningkatan biaya operasional sebesar $6 \%$, berdasarkan hasil perhitungan sejumlah kriteria kelayakan investasi, industri kecil tempe di Kecamatan Kalideres sudah tidak layak dilaksanakan dan sebaiknya tidak dilanjutkan karena usaha akan mengalami kerugian.

Hal ini berdasarkan hasil perhitungan pada usaha responden 1, nilai NPV sebesar Rp. -30.436 .818 yaitu $(<0)$, IRR sebesar $-12,63 \%$ ( $<$ dari tingkat bunga pinjaman), dan nilai payback period sebesar 10,8 tahun (> dari lamanya waktu yang ditentukan, yaitu 10 tahun). Hasil analisis sensitivitas usaha industri kecil tempe milik responden 2 memliki nilai NPV sebesar Rp. -8.093.118, yaitu $(<0)$, IRR sebesar $-10,73 \% \%$ (< dari tingkat bunga pinjaman), dan payback period 10,5 tahun ( $>$ dari lamanya waktu yang ditentukan, yaitu 10 tahun), dan usaha milik responden 4 nilai NPV sebesar Rp. -16.628.979, yaitu (<0), IRR sebesar -10,64\% ( $<$ dari tingkat bunga pinjaman), dan payback period 10,8 tahun, (lebih besar dari lamanya waktu yang ditentukan, yaitu 10 tahun.

Penelitian ini memiliki keterbatasan di antaranya jumlah usaha industri kecil tempe di Kecamatan Kalideres yang dianalisis baru meliputi 5 usaha. Selain itu, hasil analisis sensitivitas pada penelitian ini hanya menggunakan satu skenario kenaikan sebesar laju peningkatan inflasi dan nilai tukar rupiah terhadap dollar amerika. Pada penelitian selanjutnya penting untuk melakukan dua atau tiga skenario kenaikan atau penurunan sebesar 2 atau tiga kali dari laju inflasi dan nilai tukar. Selain itu, penelitian ini tidak menganalisis optimasi kemungkinan pilihan 
investasi usaha yang bersifat gabungan (tahu dan tempe) pada pemilik usaha yang sama di Kecamatan Kalideres, Jakarta Barat.

\section{KESIMPULAN}

Berdasarkan hasil analisis kelayakan finansial menunjukkan bahwa usaha Industri Kecil Tempe di Kecamatan Kalideres layak untuk dilaksanakan, Hasil analisis usaha Industri Kecil Tempe di Kecamatan Kalideres layak dijalankan karena ke-lima pengrajin tempe memiliki nilai NPV positif, yang berarti penerimaan kas bersih lebih banyak dibandingkan dengan biaya yang dikeluarkan. Nilai BCR dari usaha ke-lima pengrajin adalah $>1$, yang artinya cash in flows sama dengan cash out flows, dalam present value disebut dengan Break Even Point (BEP), yaitu total cost sama dengan total revenue. nilai IRR yang dihasilkan dari kelima pengrajin (lebih besar) > bunga pinjaman (14\%). Dan yang terakhir, payback period yang dihasilkan dari ke-lima pengrajin tempe rata-rata menunjukkan nilai (kurang dari) < 10 tahun, sesuai dengan jangka waktu yang ditentukan yaitu 10 tahun. Dari hasil analisis tersebut, sehingga dapat dikatakan bahwa industri kecil tempe di Kecamatan Kalideres layak untuk dilakukan.

Selanjutnya, berdasarkan hasil analisis sensitivitas usaha industri kecil tempe di Kecamatan Kalideres, usaha tersebut lebih sensitif terhadap terjadinya penurunan penerimaan dan kenaikan biaya, maka usaha tidak layak dilaksanakan. Tingkat suku bunga pinjaman bank melebihi IRR. Secara ekonomi, bila dana investasi berasal dari pinjaman bank, maka investasi hanya layak untuk dilaksanakan dengan dana pinjaman bank bila IRR lebih besar dari bunga pinjaman bank. Pada penelitian ini, pengrajin tempe tidak mendapatkan dana dari pinjaman bank, melainkan menggunakan modal sendiri atau dana pribadi. Namun tetap saja, hasil analisis sensitivitas pada tiga pengrajin, yaitu (responden 1, responden 2, dan responden 4) imenunjukkan tingkat pengembalian investasi melebihi dari jangka waktu yang ditentukan yaitu 10 tahun. Selain itu nilai NPV yang dihasilkan menunjukkan nilai yang negatif, yang berarti penerimaan kas bersih lebih sedikit dibandingkan biaya yang dikeluarkan, atau dengan kata lain usaha akan mengalami kerugian.

\section{REFERENSI}

Abou-Moghli, A.A., \& Al-Abdallah, G.M. 2012. Market analysis and the feasibility of establishing small business. European Scientific Journal 8(9): 94-113.

Adriano, W., \& Anggono, A.H. 2013. Feasibility study and investment analysisTextile machineries at PT Heksatex Bandung, Indonesia. The Indonesian Journal of Business Administration 2(8): 909-920. 
Afiyah, A., Saifi, M., \& Dwiatmanto. 2015. Analisis studi kelayakan usaha pendirian home industry. Studi kasus pada home industry cokelat cozy Kademangan, Blitar. Jurnal Administrasi Bisnis 23(1): 1-11.

Anoraga, P., \& Sudantoko, D. 2002. Koperasi, kewirausahaan, dan usaha kecil. Penyalur tunggal, Rineka Cipta.

Assauri, S. (1995). Manajemen Produksi dan Operasional Edisi Keempat. Jakarta. Universitas Indonesia.

Bank Indonesia. $2017 . \quad$ Inflasi. https://www.bi.go.id/id/moneter/inflasi/data/Default.aspx (6 April 2018).

Bank Indonesia. 2017. Informasi Kurs. https://www.bi.go.id/id/moneter/informasi-kurs/Contents/Default.aspx April 2018).

Fernandez, P., Ortiz, A., \& Acín, I. F. (2016). Market Risk Premium used in 71 countries in 2016: a survey with 6,932 answers. Madrid: IESE Business School. University of Navarra.

Gittinger, J. P. (1986). Analisa ekonomi proyek-proyek pertanian. Universitas Indonesian (UI-Press).

Hartono, J. 2014. Teori Portofolio dan Analisis Investasi. Ed.8. Yogyakarta : BPFE

Husein, U. (2003). Metode Riset Akuntansi Terapan. Jakarta: Ghalia Indonesia.

ILO. 2003. Undang-Undang Republik Indonesia No 13 Tahun 2003 tentang ketenagakerjaan.

https://www.ilo.org/dyn/natlex/docs/ELECTRONIC/64764/71554/F1102622 842/IDN64764.pdf (6 April 2018).

Indradi, I., Wijayanto, D., Yulianto, T., \& Suroto. 2013. Analisis kelayakan usaha perikanan laut Kabupaten Kendal. Jurnal Saintek Perikanan 8(2): 52-56.

Kasmir dan Jakfar. 2003. Studi Kelayakan Bisnis. Kencana Prenada Media Group, Jakarta.

Kementerian Keuangan. 2017. Hasil Lelang Surat Utang Negara. http://www.djppr.kemenkeu.go.id/page/load/1857 (3 Januari 2017).

Kotler, P., \& Armstrong, G. (2008). Prinsip-prinsip pemasaran (Vol. 1). Jilid.

Kuncoro, Mudrajat. 2007. Ekonomika Industri Indonesia. Yogyakarta : CV. Andi Offset. 
Mar'atissholikhah, U., DarsonoDarsono, D., \& Nurjayanti, E. D. (2013). Analisis nilai tambah industri keripik tempe skala rumah tangga (studi kasus desa lerep kecamatan ungaran barat kabupaten semarang). MEDIAGRO, 9(2).

Maulidah, S., Pratiwi, D.W. 2010. Analisis kelayakan finansial usahatani anggur prabu bestari. AGRISE 10(3): 213-225.

Mujiningsih, M. I. (2013). Analisis kelayakan usaha dan strategi pengembangan industri kecil tempe di kecamatan matesih kabupaten karanganyar. Disertasi. Universitas Negeri Semarang.

Munawir, S. 2002. Analisis Informasi Keuangan. Edisi 4. Yogyakarta: Liberty.

Nurhayati, N., Hubeis, M., \& Raharja, S. (2012). Kelayakan dan strategi pengembangan usaha industri kecil tahu di Kabupaten Kuningan, Jawa Barat. MANAJEMEN IKM: Jurnal Manajemen Pengembangan Industri Kecil Menengah, 7(2), 111-121.

Nurainy, F., Nawansih, O., \& Sitanggang, M.M. 2015. Analisis finansial dan sensitivitas usaha kecil menengah dodol coklat. Jurnal Penelitian Pertanian Terapan 15(3): 220-225.

Oke, A., Adetayo, O., Kareem, A., \& Ayedun, W. 2015. Application of feasibility study in establishment of small and medium scale enterprises in Southwestern Nigeria. European Journal of Business and Management 7(24): 31-39.

Pratiwi, E., Hartono, I. S., \& Ir Any Suryantini, M. M. (2016). Dampak kenaikan harga kedelai terhadap kelayakan usaha industri tahu dan tempe di kota pekanbaru. Disertasi. Universitas Gadjah Mada

Rahmawati, R. (2014). Analisis usaha agribisnis industri tempe kedelai rumah tangga di Kabupaten Jember. Jurnal Relasi STIE Mandala Jember, 15.

Skousen, S. 2001. Akuntansi keuangan menengah. Edisi kesembilan, jilid satu, terjemahan. Jakarta: Salemba Empat.

Sofyan, A. (2004). Manajemen Pemasaran. Jakarta: Raja Grafindo Persada.

Soleh, M. 2003. Perbaikan Mutu dan Ketahanan Pangan Produk Olahan Hasil Industri Kecil Melalui Analisis Bahaya dan Penentuan Titik Kendali. Buletin Teknologi Pangan dan Informasi Pertanian 6(2013).

Sulastri, L. (2016). Studi Kelayakan Bisnis untuk Wirausaha.

Yuwani, S.H., Irham., \& Jamhari. 2014. Analisis kelayakan dan strategi pengembangan usaha budidaya ikan air tawar di Kabupaten Sleman. Agro Ekonomi 25(2): 135-143. 
Etty Susilowati, Haruni Kurniati Analisis Kelayakan Dan Sensitivitas: Studi Kasus Industri Kecil Tempe Kopti Semanan,

\section{Lampiran 1}

Hasil Analisis Kelayakan Usaha Industri Kecil Tempe di Kecamatan Kalideres, Jakarta Barat

\begin{tabular}{|c|c|c|c|}
\hline \multicolumn{4}{|c|}{ H. Dasuki } \\
\hline Total Investasi & 408.000 .000 & & \\
\hline Net B/CR & 1,2712 & Net $B / C R>0$ & Layak \\
\hline NPV & 350.912 .241 & $\mathrm{NPV}>0$ & Layak \\
\hline IRR & $23,990 \%$ & IRR > Tingkat Bunga 14\% & Layak \\
\hline PRP & \multicolumn{3}{|c|}{ Payback Period < Dari waktu yg ditentukan, } \\
\hline PBP & 2,804 & yaitu 10 tahun. & Layak \\
\hline \multicolumn{4}{|c|}{ Kastolani } \\
\hline Total Investasi & 180.000 .000 & & Layak \\
\hline Net B/CR & 1,2778 & Net $B / C R>0$ & Layak \\
\hline NPV & 249.816 .966 & $\mathrm{NPV}>0$ & Layak \\
\hline IRR & $31,997 \%$ & IRR > Tingkat Bunga 14\% & Layak \\
\hline & \multicolumn{3}{|c|}{ Payback Period < Dari waktu yg ditentukan, } \\
\hline PBP & 2,184 & yaitu 10 tahun. & Layak \\
\hline \multicolumn{4}{|c|}{ Rusnoto } \\
\hline Total Investasi & 180.000 .000 & & \\
\hline Net B/CR & 1,2689 & Net $B / C R>0$ & Layak \\
\hline NPV & 258.686 .593 & $\mathrm{NPV}>0$ & Layak \\
\hline IRR & $31,990 \%$ & IRR > Tingkat Bunga 14\% & Layak \\
\hline PBP & \multicolumn{3}{|c|}{ Payback Period $<$ Dari waktu yg ditentukan, } \\
\hline \multicolumn{4}{|c|}{ Kartuwi } \\
\hline Total Investasi & 240.000 .000 & & \\
\hline Net B/CR & 1,2689 & Net $B / C R>0$ & Layak \\
\hline NPV & 273.489 .405 & $\mathrm{NPV}>0$ & Layak \\
\hline IRR & $26,998 \%$ & IRR > Tingkat Bunga 14\% & Layak \\
\hline PBP & \multicolumn{3}{|c|}{$\begin{array}{l}\text { Payback Period }<\text { Dari waktu yg ditentukan, } \\
2.438 \quad \text { yaitu } 10 \text { tahun. }\end{array}$} \\
\hline \multicolumn{4}{|c|}{ Muslim } \\
\hline Total Investasi & 324.000 .000 & & \\
\hline Net B/CR & 1,3002 & Net $B / C R>0$ & Layak \\
\hline NPV & 397.155 .716 & $\mathrm{NPV}>0$ & Layak \\
\hline IRR & $28,990 \%$ & IRR > Tingkat Bunga 14\% & Layak \\
\hline PBP & 2,344 & $\begin{array}{l}\mathrm{k} \text { Period }<\text { Dari waktu yg dite } \\
\text { yaitu } 10 \text { tahun. }\end{array}$ & Layak \\
\hline
\end{tabular}


BISMA (Bisnis dan Manajemen)

Volume 10 Nomor 2, April 2018

E-ISSN 2549-7790, P-ISSN 1979-7192

Halaman 102-117

Lampiran 2

Hasil Analisis Sensitivitas Industri Kecil Tempe di Kecamatan Kalideres, Jakarta

\begin{tabular}{|c|c|c|c|}
\hline \multicolumn{4}{|c|}{ H. Dasuki } \\
\hline Total Investasi & 408.000 .000 & & \\
\hline Net B/CR & 1,1273 & Net $B / C R>0$ & Layak \\
\hline NPV & $(30.436 .818)$ & $\mathrm{NPV}<0$ & Tidak Layak \\
\hline IRR & $-12,63 \%$ & IRR < Tingkat Bunga 14\% & Tidak Layak \\
\hline PBP & 10 Tahun 8 Bulan & $\begin{array}{l}\text { Payback Period > Dari waktu } \\
\text { yg ditentukan, yaitu } 10 \text { tahun. }\end{array}$ & Tidak Layak \\
\hline \multicolumn{4}{|c|}{ Kastolani } \\
\hline Total Investasi & 180.000 .000 & & \\
\hline Net B/CR & 1,1332 & Net $B / C R>0$ & Layak \\
\hline NPV & $(8.093 .118)$ & $\mathrm{NPV}<0$ & Tidak Layak \\
\hline IRR & $-10,73 \%$ & IRR < Tingkat Bunga 14\% & Tidak Layak \\
\hline PBP & 10 Tahun 5 Bulan & $\begin{array}{l}\text { Payback Period > Dari waktu } \\
\text { yg ditentukan, yaitu } 10 \text { tahun. }\end{array}$ & Tidak Layak \\
\hline \multicolumn{4}{|c|}{ Rusnoto } \\
\hline Total Investasi & 180.000 .000 & & \\
\hline Net B/CR & 1,1235 & Net $B / C R>0$ & Layak \\
\hline NPV & 9.537 .763 & $\mathrm{NPV}>0$ & Layak \\
\hline IRR & $-11,95 \%$ & IRR < Tingkat Bunga 14\% & Tidak Layak \\
\hline PBP & 9 Tahun 5 Bulan & $\begin{array}{l}\text { Payback Period < Dari waktu } \\
\text { yg ditentukan, yaitu } 10 \text { tahun. }\end{array}$ & Layak \\
\hline \multicolumn{4}{|c|}{ Kartuwi } \\
\hline Total Investasi & 240.000 .000 & & \\
\hline Net B/CR & 1,1253 & Net $B / C R>0$ & Layak \\
\hline NPV & $(16.628 .979)$ & $\mathrm{NPV}<0$ & Tidak Layak \\
\hline IRR & $-10,64 \%$ & IRR $<$ Tingkat Bunga 14\% & Tidak Layak \\
\hline PBP & 10 Tahun 8 Bulan & $\begin{array}{l}\text { Payback Period > Dari waktu } \\
\text { yg ditentukan, yaitu } 10 \text { tahun. }\end{array}$ & Tidak Layak \\
\hline \multicolumn{4}{|c|}{ Muslim } \\
\hline Total Investasi & 324.000 .000 & & \\
\hline Net B/CR & 1,1530 & Net $B / C R>0$ & Layak \\
\hline NPV & 19.254 .142 & $\mathrm{NPV}>0$ & Layak \\
\hline IRR & $-11,95 \%$ & IRR < Tingkat Bunga 14\% & Tidak Layak \\
\hline PBP & 9 Tahun 5 Bulan & $\begin{array}{l}\text { Payback Period < Dari waktu } \\
\text { yg ditentukan, yaitu } 10 \text { tahun. }\end{array}$ & Layak \\
\hline
\end{tabular}

